\title{
OS PARADOXOS DO NOVO: SOBRE 0 CONCEITO DE TRADICÃO NA OBRA DE OCTAVIO PAZ
}

Maria Esther Maciel UFMG

RÉSUMÉ

Cet essai a le but non seulement de montrer dans quelle mesure Octavio Paz retire la charge conservatrice du concept de tradition, le revitalisant à partir de la notion de rupture, mais aussi de comparer le poète méxicain avec d'autres poètes-critiques qui ont traité cette question, comme Eliot, Pound, Goethe, Borges et Haroldo de Campos. 
Henri Meschonnic

Um dos grandes méritos da literatura moderna, segundo Octavio $\mathrm{Paz}$, foi reformular o conceito de tradição a partir da perspectiva do novo. Se, no imaginário clássico, a reverência à tradição se impunha como forma de se perpetuar o passado sem criticá-lo, os escritores modernos fundaram uma maneira criativa de com ela se relacionar: a via da negação.

Só que a negação, nesse caso, não pode ser interpretada apenas como recusa ou destruição, mas como crítica capaz de manter vivo o passado, de com ele dialogar de forma polêmica e usá-lo de um modo criador. Ou, como resumiu Haroldo de Campos, ter com ele uma relação musical (sob a forma de uma "partitura transtemporal") e não museológica (enquanto "coisa morta, preservada em formol e naftalina").'

Ao negarem a tradição greco-romana, centro da cultura ocidental, os poetas modernos estavam, segundo $\mathrm{Paz}$, reconhecendo e revitalizando criticamente essa cultura, imobilizada durante séculos pela força da repetição servil. Reconhecimento que só se tornou possível quando tomaram consciência de a ela pertencerem:

Los pueblos tradicionalistas viven inmersos en su pasado sin interrogarlo; más que tener conciencia de sus tradiciones, viven con ellas y en ellas. Aquele que sabe que pertenece a una tradición se sabe ya, implícitamente, distinto de ella, y ese saber lo lleva, tarde o temprano, a interrogarla y, a veces, negarla. La crítica de la tradición se inicia como conciencia de pertenecer a una tradición. ${ }^{2}$

Essa ruptura com a tradição central do ocidente provocou, sob a ótica paziana, não só a irrupção da tradição moderna, compreendida enquanto uma sucessão descontínua de tradições provisórias (uma desalojando a outra e fundando uma nova), como o reaparecimento, no seio desta, de outras tradições (advindas do passado nacional de cada país, das civilizações orientais ou das culturas excêntricas do Ocidente) que, durante o império milenar da cultura greco-romana, ficaram à margem da história. Em outras palavras: a negação do passado clássico e a ruptura com a ordem presente recuperou, em nome do futuro, o antigo como

1. CAMPOS, 1993. p. 257.

2. PAZ, 1974. p. 27. novidade que, por sua vez, configurou-se, paradoxalmente, como recusa das idéias modernas de futuro e de progresso ${ }^{3}$. Como explica Octavio Paz:

Lo viejo de milenios también puede acceder a la modernidad: basta con que se presente como una negación de la tradición y que nos proponga otra. Ungido por los mismos poderes polémicos que lo nuevo, lo antiquísimo no es un pasado: es un comienzo. La pasión contradictoria lo resucita, lo anima y lo convierte en nuestro contemporáneo. En el arte y en la literatura de la época moderna hay una persistente corriente arcaizante que va de la poesia popular germánica de Herder a la poesía china desenterrada por Pound, y del oriente de Delacroix al arte de Oceanía amado por Breton. Todos esos objetos, trátese de pinturas y esculturas o de poemas, tienen en común lo siguiente: cualquiera que sea la civilización a que pertenezcan, su aparición en nuestro horizonte estético significó una ruptura, un cambio. ${ }^{4}$

Daí a já mencionada relação ambígua da poesia moderna com a história concebida como sucessão. Ela ingressa no fluxo temporal, ao mesmo tempo em que faz a crítica da cronologia, colocando em coexistência o presente e o passado reinventado. Ela pluraliza, assim, à luz da agoridade, tanto o conceito de tradição quanto o de novo, evidenciando, de certa maneira, a controvertida tese de Valéry segundo a qual o poeta moderno "entra no futuro à marcha ré"

É nessa medida que o termo paziano tradição da ruptura pode designar tanto a ruptura explícita com o passado imediato quanto a ruptura silenciosa com os próprios valores da Modernidade.

Como uma das expressões paradoxais dessa tradição da ruptura, a tradição da analogia merece uma atenção especial do autor. Não só por ser a manifestação da outra voz, estando vinculada à concepção circular (portanto, mítica) do tempo, o que a torna uma oponente em potencial da Modernidade, como por estar atravessada, na poesia moderna, pela ironia (sua "gêmea adversária"), o que a torna contraditoriamente crítica, afinada com a estética da mudança e com o movimento da história.

Daí a minha discordância com Silviano Santiago, quando este, no ensaio "A permanência do discurso da tradição no modernismo

3. Cobe repraduzir aqui, em terceiro möo, um fragmento de Adorno, citado por Jouss: "Aí nos deporomos com o verdodeiro temo do sentido do trodição: aquilo que é relegodo à margem do caminho, desprezado, subjugado; oquilo que é coletado sob o nome do antiqualhas, é ó que busca refúgic o que há de vivo na trodiçōo..." (f. CAMPOS, 1993. p. 237.

4. PAZ, 1974. p. 21.

5. VALÉRY, 1991. p. 120.
REVISTA DE ESTUDOS DE LITERATURA

Belo Horizonte, v. 3, p. 21 - 33, out. 95 
brasileiro" correm separadas uma da outra na história da literatura moderna, sendo uma (a da analogia) a expressão conservadora da tradição e a outra (a da ironia) a manifestação da ruptura (esta, compreendida pelo crítico brasileiro apenas pela ótica do novo, da mudança). Nas suas palavras:

Paz define duas formas de tradição: a tradição da ruptura, esta a que me referi anteriormente, como sendo a do make-it-new glorioso, e a tradição da analogia. A aproximação crítica das duas formas de tradição nunca chega a emergir no raciocínio ou no texto de Paz. Eis um livro a ser feito que investigaria o papel da tradição da analogia ao lado, ou mesmo dentro, da tradição da ruptura, enquanto articuladores do pensamento moderno.

Por ser inseparável da ironia e manter com esta uma relação de conjunção e disjunção ao mesmo tempo, a tradição da analogia é, sim, investigada por Octavio Paz enquanto uma das forças paradoxais (e que corre dentro) da tradição da ruptura, esta, como vimos, compreendida em toda a sua dimensão contraditória. O que fica claro neste segmento de Los hijos del limo:

Ironía y analogía son irreconciliables. La primera es la hija del tiempo lineal, sucesivo e irrepetible; la segunda es la manifestación del tiempo cíclico: el futuro está en el pasado y ambos en el presente. La analogia se inserta en el tiempo del mito, y más: es su fundamento; la ironía pertenece al tiempo histórico, es la consecuencia (y la conciencia) de la história. La analogía convierte a la ironía en una variación más del abanico de las semejanzas, pero la ironía desgarra el abanico. La ironía es la herida por la que se desangra la analogía; es la excepción, el accidente fatal, en el doble sentido del término: lo necesario y lo infausto. La ironía muestra que, si el universo es una escritura, cada traducción de esa escritura es distinta, y que el concierto de las correspondencias es un galimatías babélico. ${ }^{g}$

Um jogo, cujo movimento não prioriza ou escamoteia um ou outro elemento, mas os coloca em permanente diálogo. E é precisamente enquanto força roída e relativizada pela ironia que a analogia possibilita o movimento da tradição da ruptura.

\footnotetext{
6. SANTIAGO, 1990. p. 94-123.

7. SANTIAGO, 1990. p. 97

8. PAZ, 1974. p. 11
}

Para demononispol em http://www.letras.ufmg.br/poslit moderna, Paz percorre vários autores de diferentes momentos da Modernidade, dentre os quais destacam-se Baudelaire e Mallarmé, em cujas obras o embate entre ironia e analogia se faz ver de maneira mais radical.

O poeta crítico mostra que, em Baudelaire, a analogia evidenciada na famosa teoria das correspondências - longe de buscar uma anulação da distância e das diferenças entre as distintas linguagens do mundo numa totalidade harmônica, revela um oco (o estranho, o bizarro, a morte) por onde desaparecem o sentido da linguagem e a presença da realidade. Oco que será contemplado de maneira mais efetiva por Mallarmé que, ao tratar o universo como texto e vice-versa, trata ambos como metáfora do nada, como um Livro que não existe senão enquanto silêncio.

A consciência irônica desse oco que há no cèntro da analogia é, segundo $\mathrm{Paz}$, o cerne da diferença entre o pensamento analógico moderno e o renascentista. Como ele explica, enquanto para Dante, "la analogía reposa sobre una ontologia", apresentando no seu centro um nó, esse centro, para os poetas modernos, é vazio; enquanto a analogia clássica busca a unificação da pluralidade a partir da idéia de Deus ou da Santíssima Trindade, a moderna desaloja a divindade, fragmenta a unidade e se constitui como uma combinatória de linguagens distintas. ${ }^{9}$

Assim, pode-se afirmar que, para $\mathrm{Paz}$, se os poetas buscaram no solo do século XVI uma velha tradição, em tudo dissonante dos valores do mundo moderno (e, portanto, sua negação), eles não deixaram de, por outro lado, reprocessá-la de maneira crítica e criativa, convertendo-a numa prática também moderna.

A analogia dos poetas modernos configurar-se-ia, assim, como uma tradução da analogia antiga, na acepção paziana da palavra tradução:

Para nosotros traducción es transmutación, metáfora: una forma del cambio y la ruptura; por tanto, una manera de asegurar la continuidad de nuestro pasado al transformarlo en diálogo con otras civilizaciones. ${ }^{10}$

Com essa definição de tradução, interligada aos conceitos de metáfora e analogia, Paz também traduz o seu próprio conceito de tradição, do qual se vale para ler a poesia moderna.

9. PAZ, 1974. p. 113.

10. PAZ, 1992-b. p. 165. 
Pode-se dizer que, se Paz elaborou-o teoricamente, como que dando continuidade ao que, para os poetas modernos europeus, era uma relação mais poética do que teórica e que, com os norte-americanos Eliot e Pound, passou a ser pensada e problematizada de maneira mais efetiva, o fato de essa presença da tradição na poesia moderna ter sido investigada em relação à idéia de ruptura só foi possível em decorrência da relação que o próprio Paz tem com essas questōes. Certamente, se ele tivesse uma visão do passado fundada na lógica do formol, ele ou tomaria a tradição da ruptura apenas como recusa destruidora desse passado ou, caso insistisse em nela detectar a presença deste, o faria como um conservador, à revelia da idéia de "novo".

Ao contrário, Paz, consciente de que "una tradición que se petrifica sólo prolonga a la muerte"l", retira a carga conservadora do conceito convencional de tradição, pluralizando-a e retraçando-a sob a ótica da invenção.

Quanto às prováveis similitudes entre esse conceito e o que elaborou T. S. Eliot, pode-se afirmar que existem pontos provisórios de afinidade entre eles. Como se verá, Paz continua as reflexōes de Eliot, quando questiona a tradição enquanto um legado a ser repetido resignadamente pelas novas gerações e se propōe a redimensioná-la a partir da idéia do novo. Mas delas se distancia, seja por considerar o passado como uma recriação do presente e não como uma permanência respeitosamente modificável pelo novo, seja por descentralizar a noção de tradição (em Eliot centrada na cultura européia), transformando-a em um leque de passados e geografias diversas.

Eliot, no seu eminente ensaio "Tradition and individual talent", posiciona-se não apenas contra a supervalorização da idéia de originalidade ("nossa tendência em insistir, quando elogiamos um poeta, sobre os aspectos de sua obra nos quais ele menos se assemelha a qualquer outro"'12), como também contra o que designou de "aderência cega" aos êxitos das geraçōes anteriores. E propõe que tenhamos o que ele chama de "sentido histórico", isto é, "a percepção, não apenas do passadismo do passado (the pastness of the past), mas da sua presença"13 enquanto valor $e$ referência para a literatura do presente.

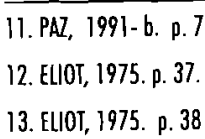

Pode-se dizer que, mesmo arejando o conceito tradicional de tradição, retirando-o da sua clausura museológica e fazendo-o coexistir numa relação sincrônica - com a noção de novo, Eliot, já no ensaio de 1917 , insiste na superioridade do passado. Ele é tomado como uma ordem preexistente, cuja totalidade é alterada pela irrupção do novo, mas à qual este deve se adaptar harmonicamente, sob pena de não sobreviver, visto que essa adaptação é o seu teste de valor.

$\mathrm{Na}$ trilha idealista de Hegel, Eliot acredita que passado e presente podem conviver harmonicamente - um modificado pelo outro - numa nova síntese que só poderá ser alterada pela emergência de uma outra novidade que, por sua vez, se integrará ao conjunto modificado:

A ordem existente é completa antes que a nova obra chegue; para que a ordem persista após a introdução da novidade, a totalidade da ordem deve ser, mesmo que levemente, alterada: e assim as relaçōes, proporçôes, valores de cada obra de arte rumo ao todo são reajustados; e daí advém a conformidade entre o antigo e o novo. ${ }^{14}$

Dessa postura de conciliação harmônica diverge Octavio $\mathrm{Paz}$ quando afirma existir uma permanente tensão entre as gerações literárias, uma "lucha a muerte" entre os poetas e seus mestres, e defende que "lo que debemos hacer con los modelos clásicos es cambiarlos, transformarlos, incluso deformarlos"'s, a partir de uma "filialidad polémica" e não apaziguadora à tradição.

Se considerarmos ainda os ensaios posteriores de T.S. Eliot, sobretudo o What is a classic?, de 1944, atestaremos uma tentativa mais efetiva do poeta anglo-americano de restaurar uma tradição central, no caso a européia (na qual, para ele, Virgílio ocupa um lugar soberano), que pudesse funcionar, no presente, como um ponto de referência universal para as literaturas do futuro. Tentativa justificada pelo próprio poeta a partir do argumento de uma suposta "maturidade literária" dessa tradição em relação a qualquer outra ${ }^{16}$.

Assim, como aponta o próprio Octavio Paz, Eliot, num movimento simetricamente inverso ao dos poetas modernos que se insurgiram contra a herança clássica, trazendo à tona outras tradições, buscou restaurar - à luz do presente - o esplendor desse legado. Embora,

14. ELIOT, 1975. p. 38-39.

15. PA2, 1992. p. 141.

16. ELIOT, 1986. p. 54 
Disponível em http://www.letras.ufmg.br/poslit
como poeta, tenha sido, segundo $\mathrm{Paz}$, um revolucionário, por introduzir a descontinuidade dentro "del discurso lineal de la estética grecoromana" e aliar ao "esplendor del Renacimiento inglés, la miseria y aridez de la urbe moderna"17

Eliot foi, inegavelmente, um precursor de $\mathrm{Paz}$, ao reavaliar - a partir de uma visão sincrônica da história literária - a importância do passado em relação às novas gerações e vice-versa. Como o foi também Pound, ao trazer para o presente, sob o lema do make it new e através de justaposiçōes temporais, outras tradições que não apenas a européia, ainda que esta tenha sido a grande privilegiada em sua paideuma. Mas, inversamente a Eliot, Pound prioriza o que há de original e de novo em obras do passado e não o que permanece da tradição (ainda que alterada pela intervenção do novo) nas obras do presente. "Literatura é novidade que permanece novidade", assegura ele ${ }^{18}$.

Quando Paz, em Las trampas de la fe, recupera, sob a ótica da estética da recepção, a obra da poeta e pensadora mexicana Sór Juana Inés de la Cruz, ele o faz de maneira mais afim à de Pound, por detectar o que de novo essa obra apresentava em relação à literatura predominante na língua espanhola do século XVII e em que medida ela antecipou traços da moderna poesia européia (particularmente a de Mallarmé). Seguindo o princípio do make it new, ele a lê com os olhos de um leitor do século XX e, portanto, dá-lhe um outro rosto e um novo alento, revalorizando ainda a própria estética barroca, em suas surpreendentes afinidades com a arte de vanguarda do nosso século. Sem, contudo, deixar de investigar profundamente o contexto político e econômico da "Nova Espanha" setecentista, as condiçôes literárias do tempo, a recepção (marcada por censuras e proibições) que a obra de Sór Juana teve da sociedade, bem como a própria biografia da escritora. O que Pound provavelmente não faria, por privilegiar a questão estética.

Por outro lado, quando se empenha em detectar a presença da tradição no novo, através da leitura que faz da poesia moderna, Paz se avizinha mais de Eliot. Do qual se afasta novamente, tanto por não confundir presença com permanência, quanto por tratar a tradição também como um conjunto de tradiçōes, das mais recentes às mais remotas, das mais explícitas às mais subterrâneas.

17. PAZ, 1986. p. 78.

18. POUND, 1985. p. 33.
Disponível em http://www.letras.ufmg.br/poslit

Assim, ao pluralizar o conceito de novo, descentralizar a noção de tradição e dialetizá-la pela noção de ruptura, Octavio Paz opta por uma terceira via, mais próxima talvez da de Borges, fundada numa poética da intertextualidade. E mais: trata a questão da tradição também no âmbito complexo da realidade latino-americana, de onde emerge a problemática da "identidade cultural", da qual não se ocuparam os poetas-críticos do modernism norte-americano.

$\mathrm{Na}$ esteira do Borges de "Kafka y sus precursores", Octavio Paz acredita que ao poeta (concebido como um leitor-tradutor-crítico de outros poetas) cabe eleger seus próprios clássicos e subvertê-los ${ }^{19}$. Se essa eleição define esse próprio poeta, a subversão se configura como uma forma de homenagear esses clássicos, porque, como acredita Paz, "al negar la tradición, la prolongamos; al imitar a nuestros predecesores, los cambiamos". A fidelidade à tradição, nesse caso, se manifesta, paradoxalmente, através da traição. E vice-versa.

Ao descrever e analisar a complexa relação dos poetas modernistas hispano-americanos com a tradição, esta desdobrada em várias (a tradição hispânica, a tradição central do Ocidente, a tradição moderna européia e as tradiçōes americanas do passado pré-colombiano), Paz mostra esse jogo tradução/traição como ponto nodal da conquista hispano-americana de sua identidade literária.

Oscilando entre o desejo de ingressar na aventura moderna deflagrada pelos europeus ("enlazar-se a una tradición universal"), depois de um longo período de confinamento nos "subúrbios da história", e a procura de um rosto para a literatura de seu próprio continente, até então um ramo do modelo literário peninsular, os poetas modernistas, segundo $\mathrm{Paz}$, deixaram sua terra rumo a Paris. Apropriaram-se da modernidade européia e a reinventaram dentro da língua espanhola (que, assim, também foi alterada), além de descobrirem, no afã de romperem com os cânones literários de Madrid, uma outra tradição hispânica, a da versificação rítmica, que os conduziram à intensa exploração analógica da linguagem. ${ }^{20}$ Mas, nesse movimento de assimilação (diríamos, devoração) da modernidade francesa e da antiga tradição rítmica espanhola, os poetas modernistas não estavam, conforme Paz, se recusando a ser americanos. Aliás, foi precisamente esse desterro, em busca do outro, que os levou à

19. PAZ, 1992-0. p. 147.

20. Cf. PAZ, 1991. p. 25-26.

REVISTA DE ESTUDOS DE LITERATURA Belo Horizonte, v. 3, p. 21 - 33, out. 95 
descoberta (ou invenção) de suas próprias raízes e à certeza de que "la verdadera aventura estaba en América":

La experiencia de estos poetas y escritores confirma que para volver a nuestra casa es necesario primero arriesgarse a abandonarla. Sólo regresa el hijo pródigo. Reprocharle a la literatura hispanoamericana rue sólo el desarraigo nos permitió recordar nuestra porción de realidad. La distancia fue la condición del descubrimiento.

Daí, para Paz, o cosmopolitismo dos modernistas (e também, logo depois, dos poetas de vanguarda) ter sido uma reinvenção do americanismo; o desenraizamento, um regresso ao subsolo hispânico; a assimilação da tradição moderna européia, uma ruptura (e um prolongamento) desta tradição. Movimento que, por ter sido feito através do entrecruzamento de linguagens e culturas, revitalizou tanto a poesia hispano-americana quanto a poesia espanhola, contribuindo igualmente para a pluralização e o redimensionamento da tradição moderna da poesia ocidental. Como afirma Paz, "hoy nadie niega la existencia de una literatura hispanoamericana, dueña de rasgos propios, distinta de la española y que cuenta con algunas obras que son también distintas e singulares"22.

Assim, eliminando o antagonismo entre cosmopolitismo e americanismo e tratando-os como opostos complementares, Paz relê a ambivalência da modernidade hispano-americana pela via da intertextualidade, compreendida não como uma troca de dívidas e influências entre autores, mas como um diálogo polêmico de geraçóes, tradiçōes, leituras e linguagens, em que as hierarquias valorativas são abolidas e as velhas noçōes de original, cópia e autoria são relativizadas. E nesse sentido que ele corrobora a teoria da recepção (e da tradução) de Borges e reformula também o conceito de universalidade, tradicionalmente visto sob o prisma de uma suposta superioridade da cultura européia em relação às outras (vide Eliot), seja pelo fato de ter vindo antes ou ser considerada mais "evoluída".

Pode-se dizer que Paz, sobretudo por negar que as artes progridem na mesma proporção do progresso econômico ("Dudo que la relación entre prosperidad económica y excelencia artística sea la de causa y efecto. No se puede llamar 'subdesarrollados' a Kavafis, Borges,

21. PAZ, 1989. p. 19.

22. PAZ, 1979. p. 42
Unamuno, Reyes, a pesar de la situación marginal de Grecia, España y América Latina." ${ }^{23}$ ), toma o universal como um sistema descentrado, movido por choques e confluências, onde as diferenças, longe de se anularem ou convergirem para uma grande síntese homogênea e harmoniosa (à feição da Weltliteratur goetheana), se conjugam, se debatem, se dispersam e se modificam simultaneamente. Como se vê, uma concepção analógica, considerando-se que o conceito paziano de analogia, marcado pelo movimento, não implica nem o excesso de afinidade entre os termos, nem o de oposição, o que garante uma relativa autonomia de um em relação ao outro.

Não se pode negar, entretanto, que existam pontos em comum entre Paz e Goethe, considerando-se que este formulou um projeto de universalidade pluralista (que também era uma espécie de projeto de "modernidade", como esclareceu Antoine Berman), que consistia, em termos gerais, na "coexistência ativa de todas as literaturas contemporâneas" de todas as nações do mundo, na qual a tradução tinha um papel fundamental. ${ }^{24}$

A diferença consiste no fato de Goethe eleger a língua e a cultura alemãs como centro desse sistema ("Car c'est la destination de l'Allemand que de s'élever à l'état de représentant de tous le citoyens du monde"25), idealizado como uma síntese harmoniosa entre o um e o diverso, o nós e os outros:

La littérature mondiale est l'espace spirituel dans lequel les contemporains, quelle que soit leur nationalité, se rencontrent, s'associent et agissent en commun. ${ }^{26}$

$\mathrm{Na}$ visão de $\mathrm{Paz}$, para quem o universal se abre para um leque de tradições diversas e a relação entre o eu e o outro passa pela experiência ambivalente da otredad (a percepção simultânea de que somos outros sem deixarmos de ser o que somos), fica implícito um traço antropofágico, inerente a vários pensadores contemporâneos da América Latina, sobretudo os brasileiros (cito Haroldo de Campos, Leyla Perrone e Silviano Santiago) que, reaproveitando o conceito de antropofagia de Oswald de Andrade,

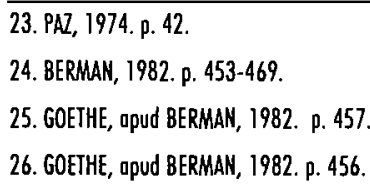


reformularam, sob a ótica da diferença latino-americana, a discussão sobre intertextualidade, universalidade e identidade cultural.

Embora Paz não faça qualquer referência à antropofagia oswaldiana, que, segundo Leyla Perrone, "nos permite superar a angústia da influência, acabar com todo o complexo de inferioridade por ter vindo depois, resolver os problemas de má consciência patriótica que nos levam a oscilar entre a admiração beata da cultura européia e as reivindicaçōes estreitas e xenófobas pelo autenticamente nacional" ${ }^{21}$, esta se faz perceber na maneira como ele lê a relação dos modernos poetas hispano-americanos com a tradição, o jogo dialógico entre cosmopolitismo e americanismo, a identidade e a diferença.

O que justifica a presença insistente de Octavio Paz (através de referências e citaçōes) no ensaio "Da razão antropofágica: diálogo e diferença na cultura brasileira", de Haroldo de Campos ${ }^{28}$, onde o poetacrítico brasileiro transforma a antropofagia oswaldiana (definida como "pensamento da devoração crítica do legado cultural universal sob o ponto de vista do "mau selvagem", devorador de brancos, antropófago" "29) em um conceito operacional, capaz de resolver, pela via da transculturação, o embate diferencial das literaturas chamadas periféricas com a literatura européia e outras tradiçōes. Questão também tratada, sob a lógica da diferença, por Silviano Santiago, não obstante este conduza suas reflexōes rumo à constatação explícita de uma suposta superioridade dos "textos descolonizados" da literatura latino-americana em relação aos da "metrópole", sob o argumento de que contêm "em si uma representação do texto dominante e uma resposta a esta representação no próprio nível da fabulação" ${ }^{30}$. O que destoa, certamente, da idéia de "transculturação recíproca" adotada - sob a ótica analógica - por Octavio Paz.

Como se pode observar, a problemática da tradição na obra de Octavio Paz é complexa e se vincula a outros conceitos do autor, como os de analogia e otredad, estando também em contínuo diálogo com outras abordagens da questão feitas por poetas e críticos de distintas épocas e geografias. Além disso, encontra-se visceralmente atrelada à noção de "novo". Este, compreendido em toda a sua dimensão paradoxal, já que pode comportar tanto o passado reinventado quanto o futuro imprevisível.

27. PERRONE-MOISÉS, 1990. p. 98.

28. CAMPOS, 1993. p. 231-255.

29. CAMPOS, 1993. p. 234. Recorre meu.

30. SANTIAGO, 1982. p. 23-24.

\section{REFERENCIAS BIBLIOGRIFICAS}

1. OE OCTAVIO PAI

Convergencios. México: Seix Barrol, 1992- o. Corriente olferno. Mexico: Siglo XXI 1984 Cuodrivio. Méxica: Jooquín Mortiz, 1991-a. El orco Y lo lira. México: Fondo de Culturo Económico, 1986 El signa y el garobato. Méxica: Jooquim Mortiz, 1992-b. In/mediociones. Barcelona: Seix Borrol, 1979. Lo otho voz; paesío y fin de siglo. México: Seix Borrol 1990 Los hijos del limo. Barcelono: Seix Barrol, 1974.

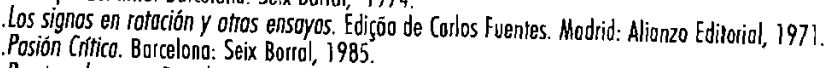
Puertos ol compo. Barcelono: Sejx Borrol, 1989 Poesio en movimiento. México: Siglo XXI, 1991-b.

Sor Juano de la Cruz o las trompos de la fe. México: Fondo de Culturo Econónico 1982 . Troduccion: literoturo y literolidad. Barcelono: Tusquets, 1971.

2. GERAL

BELU770, Ano Moria (org.) Modernidade: vonguordos ontisticas na Americo Latino. São Poulo: Memorio/UNESP, 1990 BERMAN, Antoine. Goethe: troduction et littérofure mondiole. Poétique, Poris, n. 52, nov. 1982.

BORGES, Jorge Luis. Obros completos (1923-1972). Buenos Aires: Emecé, 1974.

CAMPOS, Horoldo de. Metolinguogem e outros metos. Sōo Poula: Perspectivo, 1993.

- O seqüestro do borroco na formasāo da literatura brosileiro. Solvadodr: Coso de Jarge Amado, 1989.

C. Poesia y modernidod. Vuelto. México, n. 99, Feb. 1985

CHIAMP. Irlemor (org.). Fundodores do madernidade. Söo Paulo: Ático, 1992.

COMPAGNON, Antoine. Les cinq porodoxes de la modernits. Poris: Seuil, 1990

ELIDT, T.S. On poetry and poets. Londan: Faber \& Fober, 1986.

Selected prose. london: Faber \& Fober, 1975 .

MACIEL Mario Esther. Octovio Poz: Rupturo e Convergêncio. Ensoios de Semiótico. Belo Horizonte: UFMG, n.26, 1992-1993. MENEZES, Philadelpho. A crise do passodo. São Paula: Experimento, 1994.

MONEGAL, Énir R. Borges e Poz: um diólogo de textos críticos. Borges: umo poético da leituro. Sõo Poulo: Perspectiva, 1980 PERRONE-MOISES, Leylo. Flores da escrivaninho. Sỗ Poulo: Componhio dos Letros, 1990 POUND, Ezro. ABC do Literofura. Sāo Pouío: Cullitix, 1985. . A orte da poesio. Sô. Paulo: Cultix, 1976 .

ROSENBERG, Horald. Lo trodición de lo nueva. Madrid: Monte Ávila, 1969.

SANTIAGO, Silviano. Nos molhos do letro. Sõo Poulo: Cio. dos Letros, 1990. Vole quanto pesa. Rio de Joneiro: Poz e Terro, 1982

VAléRY, Poul. Variedodes. São Paulo: lluminuros, 1991.

VERANI, Hugo J. Los vonguordios literorios en hispono-americo. México: Fondo de Culturo Económico, 1990 